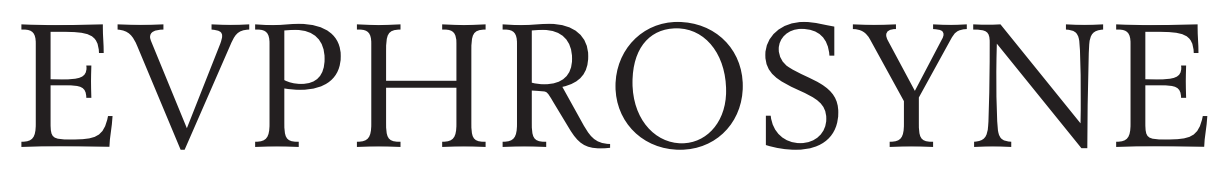
REVISTA DE FILOLOGIA CLÁSSICA

\author{
NOVA SÉRIE \\ VOLUME XLIV
}

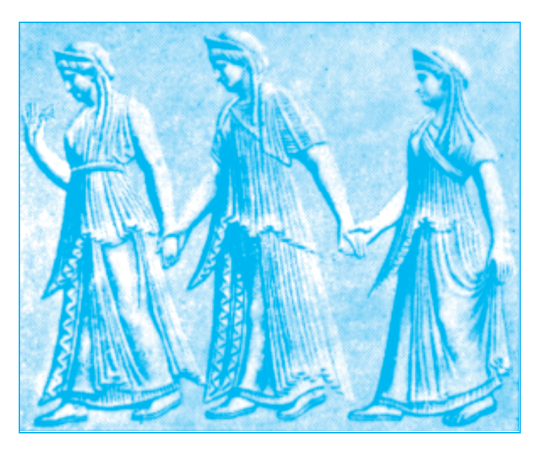

CENTRO DE ESTUDOS CLÁSSICOS

FACULDADE DE LETRAS DE LISBOA 


\section{E V P H R O S Y N E}

REVISTA DE FILOLOGIA CLÁSSICA

$*$

CENTRO DE ESTUDOS CLÁSSICOS

FACULDADE DE LETRAS DE LISBOA

PT - 1600-214 LISBOA

PORTUGAL

e-mail: centro.classicos@letras.ulisboa.pt

sítio electrónico: http://www.tmp.letras.ulisboa.pt/cec

DIRECTORA

Maria Cristina Castro-Maia de Sousa Pimentel

COMISSÃo DE REDACÇÃo

abel do Nascimento Pena, Ana Maria Sanchez Tarrío, Arnaldo Monteiro do Espírito Santo, José Pedro Silva Santos Serra, Manuel José de Sousa Barbosa, Paulo Farmhouse Alberto, Vanda Maria COUTINHO Garrido ANASTÁcio

Conselho Científico

Aires Augusto do Nascimento (U. Lisboa), Carlos Santini (U. Perugia), Carmen Codoñer Merino (U. Salamanca), Emilio SuÁrez de la Torre (U. Pompeu Fabra), JoËl Thomas (U. Perpignan), José Manuel Díaz de Bustamante (U. Santiago de Compostela), Manuel Alexandre Júnior (U. Lisboa), Marc Mayer y Olivé (U. Barcelona), Paolo Fedeli (U. Bari), Thomas Earle (U. Oxford)

\section{Conselho de Arbitragem Científica}

Alberto Bernabé Pajares (U. Complutense de Madrid), Ángel Urbán Fernández (U. Córdoba), Aurelio Pérez Jiménez (U. Málaga), María Adelaida Andres (U. Salamanca), Carlos Morais (U. Aveiro), Carmen Morenilla Talens (U. Valencia), Cristobal Macías Villalobos (U. Málaga), María Elisa Lage Cotos (U. Santiago de Compostela), Eustaquio Sánchez Salor (U. Extremadura), Fabio StoK (U. Roma II - Tor Vergata), Federico Russo (U. Konstanz), Grant A. Nelsestuen (U. Wiscounsin), Graziana Brescia (U. Foggia), Gregorio Rodríguez Herrera (U. Las Palmas de Gran Canaria), Iñigo Ruiz ArZalluz (U. País Vasco), José María Maestre Maestre (U. Cádiz), Jesús-María Nieto Ibáñez (U. León), Joaquim Pinheiro (U. Madeira), Manuel Lopez Muñoz (U. Almería), Nuno Simões Rodrigues (U. Lisboa), RAmiro GonzÁlez Delgado (U. Extremadura), Richard Marshall (U. Oxford), Rosalba Dimundo (U. Bari), Rossana Guglielmetti (U. Milano), Santiago Lopez Moreda (U. Extremadura), Sebastião Tavares de Pinho (U. Coimbra), Silvana Rocca (U. Genova)

Tiragem 500 exemplares

Depósito legal 178089/02

ISSN 0870-0133

\section{PUBLICAÇÃO ANUAL SUJEITA A ARBITRAGEM CIENTÍFICA}

REFERENCIADA EM

L'Année Philologigue | Arts and Humanities Citation Index | Bibliographie internationale de l'Humanisme et de la Remanissance | CSA Linguistics and Language Behavior Abstracts | Dialnet | EBSCO | ERIH Plus | Latindex | Medioevo Latino | SCOPUS 


\section{EVPHROSYNE REVISTA DE FILOLOGIA CLÁSSICA}

NOVA SÉRIE - VOLUME XLIV 



\title{
En la estela de Horacio: una epístola latina inédita de Giacinto Frangipane
}

\author{
EduARdo del Pino GonzÁlez \\ Universidad de Cádiz \\ eduardo.delpino@uca.es
}

\section{Introducción}

Es conocida la influencia de las Epístolas de Horacio en el Renacimiento ya desde que Petrarca compusiera sus Epistolae metricae. El auge de las epístolas en verso (relacionadas con las sátiras ya desde la propia concepción de Horacio) condujo además al nacimiento del genero llamado "epístolas horacianas" en la literatura vernácula ${ }^{1}$.

* Recebido em 31-12-2015; aceite para publicação em 28-04-2016.

** Este trabajo se enmarca en el Proyecto de Investigación FFI2015-64490-p financiado por el Ministerio de Educación y Ciencia español, así como en la Red Internacional de Excelencia FFI2015-69200-REDT. Ha sido revisado por los profesores Maurizio Campanelli, José M. ${ }^{a}$ Maestre y Dirk Sacré, a quienes agradezco sus sugerencias.

1 Sobre la influencia de Horacio pueden verse los trabajos clásicos de G. HigHET, The Classical Tradition. Greek and Roman Influences on Western Literature, London, 2015, pp. 225-228; 244-250 (= Highet, The Classical Tradition..., Oxford, 1949); R. LidA DE MalKiel, "Horacio en la literatura mundial", capítulo de La Tradición Clásica en España, Barcelona, 1975, pp. 255-267 (= Revista de Filología Hispánica, 2, 1940, 370-378); M. MenÉndez Pelayo, Horacio en España, Madrid, 1877; M. Menéndez Pelayo, Historia de las ideas estéticas en España, 5 vols., Madrid, 1962, vol. I, pp. 121-143; vol. II, pp. 295-359. Sobre las llamadas "epístolas horacianas" son también clásicos A. G. ReIchenberger, "Boscán’s Epístola a Mendoza”, Hispanic Review, 17, 1949, 1-17 y E. L. Rivers, "The Horatian Epistle and its Introduction into Spanish Literature", Hispanic Review, 22, 1954, 175-94. Del interés de este aspecto de la tradición clásica, sobre todo en el hispanismo, dan idea publicaciones recientes como E. FolSALBA, "Acerca del horacianismo de la epístola poética siglodorista: algunas cuestiones previas", eHumanista, 19, 2011, 357-375, con bibliografía actualizada. Sobre la proximidad de sátiras y epístolas en verso, y sus peculiaridades en el Renacimiento, puede verse B. Pozuelo Calero, "Méthodologie pour l'analyse des satires formelles néolatines", en R. de Smet (ed.), La Satire Humaniste. Actes du Colloque international des 31 mars, 1 et 2 avril 1993, Bruxelles, 1994, pp. 19-48; B. Pozuelo Calero, "De la sátira epistolar y la carta en verso latinas a la epístola moral vernácula", en B. López Bueno (ed.), La epístola. V Encuentro Internacional sobre Poesía del Siglo de Oro (Universidades de Sevilla y Córdoba, 23-26 de noviembre de 1998), Sevilla, 2000, pp. 61-99; E. DEL PINO, "Marco genérico de las Epístolas: el sermo horaciano" y "Las Epístolas de Verzosa sermones horacianos", en 
El caso es que escribir epístolas de cuño horaciano se convirtió en uno de los ejerccios más habituales del escritor renacentista y fue también frecuente su envío o su lectura en academias y reuniones similares.

En el presente trabajo editaremos, traduciremos y comentaremos una epístola latina en verso conservada inédita en la Biblioteca Vaticana (ms. Vat. lat. 5225, iv, f. 879r-880r) compuesta por Giacinto Frangipane para el español Juan de Verzosa ${ }^{2}$. Se trata de una epístola horaciana en la que un italiano no muy conocido, Giacinto Frangipane, hace una pequeña receptio de los Epistolarum libri de Juan de Verzosa, según la hipótesis que queremos establecer en este trabajo.

Comenzaremos exponiendo brevemente los datos biográficos de Verzosa y Frangipane que permiten entender su relación.

\section{Datos biográficos del español Juan de Verzosa}

El humanista hispano-latino Juan de Verzosa (Zaragoza 1520/21 - Roma 1574) es uno de los mejores exponentes de la influencia de Horacio de la que venimos hablando y de la permanente vinculación italiana del Renacimiento español, que no sólo atañe al siglo XV sino que abarca también todo el XVI. Hizo sus primeros estudios en su ciudad natal y con dieciséis años marchó a París para completarlos, donde ya entonces dio clases de griego. Continuó con esta docencia en Lovaina entre 1544 y 1546, y a partir de entonces sirvió a la diplomacia de Carlos V y de Felipe II (como secretario de Diego Hurtado de Mendoza, de Gonzalo Pérez y de Francisco Vargas). Con este motivo asistió a la primera fase del Concilio de Trento, vivió en Siena y Roma, y residió en la Corte filipina tanto en Londres como en Bruselas. En 1559 fue enviado a Roma para servir a la Embajada española, recibió el cargo de director de su Archivo en 1562 y ya no salió de la Urbe hasta su muerte 3 .

Juan de Verzosa sólo publicó en vida un pequeño manual de prosodia para sus alumnos. Pero dejó manuscritos unos Anales del reinado de Felipe $\mathrm{II}^{4}$ y un libro de elegías titulado Charina siue Amores ${ }^{5}$. A lo largo de toda su vida, además (al menos desde 1548), fue componiendo epístolas en verso, que en

E. del Pino, Juan de Verzosa. Epístolas, Madrid-Alcañiz, 2006, vol. I, pp. LXXI-LXXVI; CXXXII-CXXXIII. Para el humanismo hispano-latino se ha señalado además un periodo de horacianismo intenso a partir de la publicación de la Bernardina de Vilches en 1544. Véase J. F. Alcina Rovira, "Tendences et caractéristiques de la poésie hispano-latine de la Renaissance”, en A. Redondo (ed.), L'Humanisme dans les lettres espagnoles (XIXe Coloque International d'Études Humanistes, Tours 5-7 juillet 1976), Paris, 1979, pp. 133-149 (en especial 137-141).

2 Agradecemos al profesor I. García Pinilla habernos dado noticia de la localización del texto. Aunque no conocemos la letra de Frangipane, de las notas críticas a la edición parece deducirse que el manuscrito no es de manos del autor, como veremos en adelante. Igual que en el caso de Giacinto, utilizaré nombres propios italianos en el caso de estos personajes.

3 Vid. J. M. MaEstre, Juan de Verzosa. Anales del reinado de Felipe II, Madrid-Alcañiz, 2002, pp. XXIII-LI. Hay reseñas biográficas también en M. ${ }^{a}$ DEl MAR PéreZ-Morillo, Juan de Verzosa. Charina siue Amores, Madrid-Alcañiz, 2002, pp. XVII-XXI; y E. DEL PINO, op. cit., pp. XXVII-XLV.

${ }^{4}$ Editado modernamente por J. M. ${ }^{\text {a }}$ MAESTRE, op. cit.

${ }^{5}$ Editado modernamente por M. ${ }^{a}$ DEL MAR PÉREZ Morillo, op. cit. 
el momento de su muerte constituían ya un manuscrito con las composiciones ordenadas y divididas en cuatro libros, aunque el último permanecía inacabado. El autor legó el manuscrito en testamento a su buen amigo el arzobispo de Montreal (Sicilia) Luis de Torres y este encargó la publicación a su sobrino del mismo nombre, que las dio a la imprenta con el título de Ioannis Verzosae Epistolarum libri IIII, Panhormi, $1574^{6}$.

\section{Giacinto Frangipane y su coincidencia en Roma con Juan de Verzosa}

No es abundante la documentación publicada sobre Giacinto Frangipane. En algunos catálogos figura como obispo de Trieste entre el 1 de marzo de 1574 y el 8 de noviembre del mismo año, fecha de su muerte ${ }^{7}$. No obstante, Pio Paschini alude a ciertas diferencias entre el Archiduque de Austria y el papa Gregorio XIII en el nombramiento ${ }^{8}$, lo que hace comprender que realmente no tomase posesión de la sede y que incluso llegase a ella ya muerto: Giuseppe Mainati nos informa de que el friuliano no tomó posesión, pero, al haber indicado en su testamento que trasladaran a Friuli su cuerpo, fue enterrado en la catedral de la ciudad con el siguiente epitafio:

Giacinto Frangipane di Castello per somma providenza di Carlo Arciduca d'Austria ec. assunto al vescovato, la morte che lo prevenne non potè rapirgli cio ch'egli con la stima, colla pietà del'animo, colla cura della religione e coll'antichità del lignaggio aveva conseguito da sì gran principe. 1574 li [sic] 8 novembre. Imperatore Massimiliano II. Pontefice Gregorio XIII. 1575.9

La familia Frangipane tuvo tres ramas, una de Roma, otra del Friuli y la tercera de la Dalmacia. Los Frangipane de Roma se consideraban de la nobleza más antigua de la ciudad (haciendo remontar su apellido a la generosidad de la familia en uno de los desbordamientos del río: frange panem) y entroncaron con los Marqueses de Nemi. Poseyeron un palacio cerca de

${ }^{6}$ Hay noticia de todo ello, incluidos los posibles estados y emisiones de la edición de Torres (que llevó diferentes fechas en la portada y el colofón) en E. DEL PINO, op. cit., vol. I, pp. LI-LXV. Las Epístolas tuvieron también una edición moderna a cargo de J. LóPEz DE TORO, Epistolas de Juan Verzosa, Madrid, 1945, con biografía de Verzosa en pp. XIX-XXIX, ya superadas biografía y edición por las ediciones modernas de J. M. ${ }^{a}$ MAESTRE, op. cit., pp. XXIII-LI, y E. DEL PINO, op. cit.

7 Así en P. B. Gams, Series Episcoporum Ecclesiae Catholicae, Ratisbonae, 1873, s.u. Puede verse tambien en The Hierarchy of the Catholic Church. Current and historical information about its bishops and dioceses, http://www.catholic-hierarchy.org/bishop/bfranggi.html (consulta de 15 de agosto de 2015). A partir de aquí utilizaremos la sigla s.u. (sub uoce) para los diccionarios biográficos y similares.

8 Véase P. PASCHINI, Eresia e riforma cattolica: al confine orientale d'Italia, Roma, 1951, p. 30, donde dice: "L'Arciduca Carlo avrebbe voluto dare la sede di Trieste a Giacinto Frangipane di Castello, il 24 aprile 1574 Gregorio XIII proponeva all'arciduca Carlo come vescovo di Trieste il francescano Francesco Sporeno lodando le sue eccellenti qualità".

9 Véase G. Mainati, Croniche ossia Memorie Storiche Sacro-Profane di Trieste, Venezia, 1817, vol. III, pp. 117-118. 
Piazza Venezia; una capilla en la Chiesa di San Marcello al Corso, todavía conservada; y la Villa Strozzi sobre el Viminal.

La segunda de las ramas (a la que pertenecía Giacinto) era titular, por vía de casamiento, del feudo de Castello (hoy día Castelporpetto) en el Friuli; pero la familia se consideraba entroncada con la rama de la Urbe y, al menos desde Cornelio di Castello (1508-1588), adoptaron por este motivo el apellido Frangipane. Teniendo en cuenta las fechas, la procedencia y la formación de Cornelio di Castello o Frangipane, Giacinto pudo haber sido un hermano suyo $^{10}$. Pero poco más puede decirse.

Por otro parte, la vida de Cornelio Frangipane, abogado y literato, estuvo presidida por su defensa de la nobleza friuliana y de los Castellani y por sus contactos con la Reforma y con personajes como Pier Paolo Vergerio ${ }^{11}$. Así es que quizás esto tenga que ver con las dificultades de Giacinto para obtener el obispado de su tierra natal y con la escasez de documentación sobre su vida.

No obstante, aunque en el estado actual de la investigación no contemos con fuentes documentales contemporáneas, por lo dicho antes comprendemos que no tiene nada de extraño que Giacinto Frangipane viviese en Roma, incluso un largo tiempo. Que residió en ella, al menos por los años de 1565-1566, y que el español Juan de Verzosa lo conoció y tuvo cierto trato con él es algo que se desprende de la epístola 2, 29, versos 16-21 del segundo $^{12}$. La epístola estaba dedicada al mantuano Curzio Gonzaga y se enmarca cronológicamente en el tiempo en que Francesco Gonzaga, citado en ella como tal, fue obispo de Mantua: entre el 18 de mayo de 1565 y el 10 de enero de 1566. En ella Verzosa alaba el saber hacer de Curzio Gonzaga en la Corte vaticana y en sus últimos versos nombra a algunos de los participantes en las reuniones palaciegas:

\footnotetext{
Nec de natura tractas academicus aut de

Moribus et rebus uariis cum patribus, ut quid

Effundas illic temere quod mordeat illos;

Ne tuus incuset merito te Claudius et nos

In pallatinis cum Frangipane coronis. ${ }^{13}$
}

10 Es sugerencia esta de Rossana Sacchi, que considero muy acertada. Sobre los Frangipane y Cornelio véase M. CAVAZA, "Cornelio Frangipane", en Dizionario biografico degli italiani (Istituto Treccani ed.), http://www.treccani.it/enciclopedia/cornelio-frangipane_(Dizionario_Bio grafico)/ (consulta de 15 de agosto de 2015); S. Volpato, "Frangipane Familia" en C. Scalon, C. Griggio, U. Rozzo, Nuovo Liruti. Dizionario biografico dei Friulani. 2. L'età Veneta, D-M, Udine, 2009, pp. 1184-1187. M. Cavaza indica que hay documentación manuscrita sobre la familia en el Archivio Frangipane (vols. 176-178) de Giovanni di Aiello del Friuli y en la Biblioteca Comunale de Udine (Fondo principale, mss. 405, 423-424, 1544; y Fondo Vincenzo Joppi, ms. 93). Agradezco estas informaciones a las profesoras Federica Ambrosini y Rossana Sacchi.

11 Pier Paolo Vergerio (1498-1565), obispo de Capodistria, su ciudad natal, fue el primer obispo de la Iglesia de Roma que pasó a una iglesia reformada. Véase sobre él P. B. BIETENHolz, T. B. Deutscher, Contemporaries of Erasmus. A biographical register of the Renaissance and Reformation, Toronto, 1985, s.u.

12 Citaremos a partir de aquí (Verz. epist. 2, 29, 16-21 por ejemplo) conforme a E. DEL PINO, op. cit., donde la primera cifra indica el número de libro, la segunda de poema, la tercera de versos.

13 Texto latino y traducción de E. DEL PINO, op. cit., vol. II, pp. 656-659: "ni en la Academia tratas sobre la naturaleza, ni con los monseñores sobre costumbres y asuntos varios, de 
El personaje citado en el verso 19 de este texto es Claudio Gonzaga y podemos constatar en el verso siguiente que tanto él como Frangipane y Verzosa tomaban parte en las reuniones de la Corte romana.

Haremos a continuación edición crítica del texto latino de Frangipane que se encuentra en la Biblioteca Vaticana (ms. Vat. lat. 5225, iv, f. 879r-880r) y que es el centro de nuestro trabajo ${ }^{14}$. El posterior comentario de la composición nos ilustrará sobre otros participantes en esas reuniones, sobre el conocimiento que Frangipane tenía de Verzosa y la posible datación incluso de su texto.

\title{
4. Edición y traducción del poema de Giacinto Frangipane para Verzosa
}

\author{
J[acinthus] ad Verzosam ${ }^{15}$ \\ Iampridem optavi Venusino scribere versu \\ quo tantum polles unus, Verzosa diserte, \\ at numquam mea Musa ausa est tam magna subire \\ munia totque humeris non convenientia nostris. \\ Sed iam Christophori, Alciati, Baldique Philippi \\ eloquio et compulsa tuae candore Camoenae, \\ facundos inculta tuos adit illa penates, \\ ut saluere meo iubeat te nomine et oret \\ uti sibi des veniam, si te grauioribus actum \\ vel curis, studia ad tua vel mitiora reuersum, \\ insulsis numeris ${ }^{16}$ interpellarit, amice. \\ Ipse etenim noui quot quanta negotia tractas, \\ seu regi Hispano quidquid fit urbe remittis, \\ seu cum pontifice aut alio cum principe quicquid \\ illius peragis iussu: nil denique tantum est \\ quod si tu incipias ductu ratione tuoque \\ consilio non perficias, quae maxima pars est \\ virtutis laudisque tuae; sed non minus ingens \\ gloria in edendis tua nostri temporis actis \\ enitet et gratum te cunctis reddit amicis \\ principibusque, adeo ut iure ausim dicere nullum \\ finibus Hesperiae egressum, qui promptius ac tu ${ }^{17}$ \\ omnia cognoscat, peragat iucundius ac $\mathrm{tu}^{18}$. \\ Quinetiam, si post exacta negotia fessus \\ iam gravibus curis ex urbe abscedere mauis \\ Pieridum et gelidas umbras sacrosque recessus
}

forma que sueltes allí atrevidamente lo que les pueda picar; no sea que tu Claudio te critique con razón, y también nosotros en las reuniones palaciegas con Frangipane".

${ }^{14}$ Hemos optado por la llamada edición diplomática respetando las grafías del manuscrito, incluso las incongruencias en la distribución de v/u. A pie de página añadimos las habituales notas críticas y de loci similes. También hacemos traducción española del texto. En las notas críticas sólo hay que tener en cuenta la sigla $\mathrm{V}=$ Vat. lat. 5225, iv, f. 879r-880r.

\footnotetext{
$15 \mathrm{~J}$ [acinthus] conieci.

16 numeris correxi: humeris $V$.

17 promptius ac tu conieci : promptius quam te contra grammaticam metrumque $V$.

18 iucundius ac tu conieci : iucundius quam te contra grammaticam metrumque $V$.
} 
visere Castalii dulcesque haurire liquores fontis et Aonii residere in vertice montis, consilia, ingenia et mores ritusque recentes praesentis ${ }^{19}$ Romanae Aulae, iuuenumque senumque singula facta refers, patriae qui commoda dulcis liquere ac Romae degunt, quos vexat et angit assidua ambitio atque argenti insana cupido, cunctaque pertexis ${ }^{20}$ tam suaui carmine et arte tam culta et facili, ut numerosus Horatius ${ }^{21}$ idem

pangeret aetherias iterum si exiret in oras.

Denique tam mite ingenium, facundia tanta, tam $^{22}$ lepidi gratique sales, Verzosa, tibi sunt aut in conuiniis aut in sermonibus, ut te quilibet et princeps et quilibet aulicus unum audiat, obseruet, miretur, laudet ametque. Tanta tuae est bonitas naturae, clara ut et ${ }^{23}$ ipsi Pontifici et patribus, sicque oratoribus, illi praecipue qui decedens ex urbe reuertit Hispanum ad regem, tua cui sunt optima nota Et merita erga illum, officia et pia gentis Iberae erga omnes, tibi quos deuincis tempus in omne. Ipse equidem optarem uiridem ${ }^{24}$ rubeumque galerum ${ }^{25}$, docte poeta, tibi: at metuo tua culta Camoena ne foret argenti atque auri obruta aceruo, amplius ut liquidos Parnassi cernere fontes non posset, uel si posset iam accedere nollet et, quae nunc humili cunctos oblectat auena, magnas inter opes tumida atque superba sileret. Quocirca est melius tibi quam concessit Apollo contentus sorte ut uiuas ${ }^{26}$ quasque inscia turba diuitias sequitur fugias, popularis et aurae sibila contemnas, et pulchra poemata condas in lucemque edas propriae praeconia laudis: Quin et amicorum, quos (ultimus!) ${ }^{27}$ inter adesse 28 si mihi continget post mortem ac uiuere per te, nullo unquam fuerit me tempore clarior alter. Interea Frangipanis, quem turpis habendi nulla uocat ratio uiuendi e tramite recto, quem nulla a studiis Musarum abducit honorum cura $^{29}$ suo arbitrio quos vulgus donat et aufert, te salvere iterum iubet ac deponere curas ${ }^{30}$

19 praesentis correxi: praesentes $V$.

${ }^{20}$ pertexis conieci : pectoris contra metrum $V$.

21 numerosus Horatius: cf. Ov. trist. 4, 10, 49.

22 tam correxi: iam $V$.

23 clara ut et conieci: claras ut contra metrum $V$.

24 uiridem correxi: uiride ut uidetur $V$.

25 galerum masc. gen. sicut Verg. Aen. 7, 688.

26 contentus sorte ut uiuas: cf. Hor. sat. 1, 1, 1-4.

27 (ultimus!) conieci: ultimes $V$.

28 inter adesse scripsi: interadesse $V$.

29 cura honorum: cf. Hor. carm. 4, 14, 1-2.

30 deponere curas: cf. Verg. georg. 4, 531. 
ingentes animo, dulces quae carpere somnos ${ }^{31}$

nec gustare sinunt gratae solatia uitae.

Vive igitur felix et inania praemia temne:

ipsa sibi est virtus pretium fructusque laborum.

\section{$\mathrm{J}\left[\right.$ acinto] a Verzosa ${ }^{32}$}

Ya hace tiempo, culto Verzosa, que deseo escribir en los versos del Venusino ${ }^{33}$, en los que tanto destacas tú por encima de todos; sin embargo mi Musa nunca se atrevió a afrontar un desafío tan grande y tan superior a mis fuerzas.

Pero ahora, empujada por el consejo de Cristóforo, Alciati y Filippo Baldo, y atraída por el brillo de tu Camena ${ }^{34}$,

mi Musa llega, aunque poco cultivada, hasta tu casa, sede de la elocuencia, para saludarte en mi nombre y para pedirte que la perdones

si te interrumpe, amigo, con poca gracia,

mientras tú estás ajetreado con serias preocupaciones

o estás ya dedicado a tus estudios más agradables.

Bien sé cuántos asuntos gestionas y de qué importancia, al informar al rey español de todo lo que ocurre en Roma y de todo lo que tratas por encargo suyo con el Papa o con cualquier otro de los próceres. A fin de cuentas,

no hay nada que tú emprendas, llevado por tu razón y por tu prudencia,

y que no lo lleves a cabo a la perfección: lo cual es la parte más grande

de tu virtud y de la alabanza que mereces. Y no brilla menos

tu gran gloria cuando escribes la crónica de nuestra época,

y eso te hace grato para todos los amigos y señores

hasta tal punto que con razón me atrevería a asegurar no haber salido de las fronteras

de la Hesperia ${ }^{35}$ otro que lo conozca todo con más facilidad que tú

ni que lo lleve todo a término con más éxito.

Más aún, si después de gestionar tus asuntos,

cansado ya de las graves preocupaciones, prefieres dejar la Urbe

y visitar las sombras frescas y el sagrado retiro de las Piérides

- y beber las dulces aguas de la fuente Castalia

y descansar en la cumbre del monte Aonio ${ }^{36}$-,

tú relatas entonces la forma de pensar, los caracteres, las costumbres

y formas de proceder de la actual Corte romana, así como los hechos de cada cual,

jóvenes y viejos, que dejaron las comodidades de su dulce patria

para vivir en Roma, donde los aqueja la ambición constante y el deseo insano de dinero;

y compones todo eso en unos poemas tan agradables

y con un arte a la vez tan exquisito y sencillo, que el poeta Horacio

lo haría igual si volviese a la vida.

31 carpere somnos: cf. Verg. georg. 3, 435.

32 El nombre italiano de Giacinto proviene del griego "Hyacinthos", pero las latinizaciones del mismo variaron en la época de Frangipane, lo que permite entender la inicial del autor en el título. Por otra parte, sabemos que debe tratarse de Giacinto Frangipane porque el autor aporta su apellido al final del poema.

33 En versos según el modelo del poeta de Venusia, Horacio.

34 De la Musa o producción poética de Verzosa.

35 Hispania, con respecto a Italia.

36 Es decir, si decides dedicarte a escribir poesía. Como se sabe, las Piérdides son las Musas, a las que estaba consagrada la fuente Castalia y el monte Helicón, llamado Aonio por estar en la Aonia o Beocia. 
Para colmo, Verzosa, tienes un carácter tan amable, tan gran

facilidad de palabra, una sal tan graciosa y elegante

lo mismo en los banquetes que en los corrillos,

que todos los señores y cortesanos te oyen a ti solo,

se fijan en ti, te admiran, te ensalzan y te aman.

Eres de un natural tan honesto que es famoso para el mismísimo Pontífice

y para los monseñores, y también para los embajadores

(principalmente para aquel que, dejando la Urbe,

vuelve ante el Rey español, y para el cual son conocidos tus méritos inmejorables

para con el propio Rey así como tu disponibilidad para con todos

los de la nación ibera, que quedan obligados contigo para siempre).

Sin duda que yo desearía para ti, docto poeta, el solideo verde y el rojo.

Pero temo que tu culta Camena ${ }^{37}$ se viese

tan cubierta por el montón de plata y oro

que no pudiese distinguir las limpias fuentes del Parnaso

o, si es que pudiese, no quisiera ya allegarse a ellas,

y que tu flauta sencilla que ahora deleita a todos con humilde sonido,

engreída y soberbia entre grandes riquezas, guardase silencio.

Por tanto es mejor que vivas contento con la suerte que te concedió Apolo

y que rehúyas las riquezas que persigue el vulgo ignorante - y que desprecies

los silbidos del favor cambiante del pueblo -, y que escribas en cambio

tus hermosos poemas y los publiques, lo cual será el pregón de tu propia gloria

y más aún de la de tus amigos. Si a mí (¡que soy el último!) $)^{38}$

me cupiera en suerte contarme entre ellos

$\mathrm{y}$ vivir gracias a ti tras mi muerte,

ningún otro ${ }^{39}$ será nunca más ilustre que yo.

Mientras tanto este Frangipane - al que ninguna forma indecente

de ganancia saca de la rectitud de vida,

al que ninguna preocupación por los cargos que el vulgo concede

y quita a su arbitrio lo separa de la dedicación a las Musas -

quiere ${ }^{40}$ que estas mismas te saluden de nuevo y quiten las grandes preocupaciones

de tu ánimo, esas que no te permiten coger el dulce sueño

ni disfrutar del solaz de una vida agradable.

Vive por tanto feliz y desprecia premios vacuos.

Tu misma virtud es el fruto de tus trabajos y su premio.

\section{Comentario}

\subsection{Comentario a las notas críticas}

El texto no parece de manos de su autor sino de un copista. Si atendemos a las notas críticas, veremos que los errores son propios de la copia:

37 Tu Musa o inspiración poética.

38 Parece que el copista confunde fácilmente las vocales "e" y "u", como le ha ocurrido en quam te en vez de $a c t u$. Bajo la lectura errónea ultimes debemos entender el nominativo ultimus, usado de forma parentética para enfatizar además, por un lado quizás lo reciente del conocimiento entre ambos, por otro el que Frangipane se presente para ser incluido el libro cuando parecía como veremos el último momento antes de publicación.

${ }_{39}$ Ningún otro de los personajes externos al epistolario, se entiende.

40 En el original latino en primera persona, lógicamente, porque "este Frangipane" es el propio autor del texto. 
principalmente el de los versos 22 y 23 , en cuyos finales se reitera promptius quam te y iucundius quam te, comparaciones ambas inadmisibles tanto para la métrica como para la gramática ${ }^{41}$; también el de claras ut en verso 42; y el de ultimes en el verso 60.

\subsection{Comentario a los versos $1-2$}

Dice Frangipane que él deseaba desde hacía tiempo escribir en verso horaciano, pero no se atrevía por su falta de condiciones. Y, aunque pueda ser una manifestación tópica de modestia, quizás tiene también cierta razón. Aunque la composición responde a los moldes y cauces del sermo de Horacio, cabe decir que resulta excesiva la repetición de oraciones consecutivas (adeo ut, verso 21; tam suaui, tam culta ut, versos 34-35; tam ... tanta ... tam ... ut te, versos 37-39; tanta ... ut, verso 42), así como suena también algo torpe la repetición de oraciones de relativo en los versos 31-32 y 44-47, y de la preposición erga en 46-4742. Además de esto, encontramos elisión en el final del verso 15 (lugar que habitualmente se evitaba) y en la quinta tesis de varios de ellos: 8, 34, 42 y 50 (algo que es ciertamente aceptable pero no frecuente ni especialmente "horaciano") 43.

En cualquier caso, finalmente Frangipane se decide a componer el poema y enviarlo a Verzosa, conocido como experto en ese tipo de versos. $\mathrm{Y}$ a decir verdad se conservan indicios diversos de esa fama de Verzosa.

Para empezar, Horacio tuvo una importancia grande en su formación, porque cuando llegó a Italia adquirió buena parte de su saber humanístico en la biblioteca de Hurtado de Mendoza, donde las obras horacianas estaban muy bien representadas. Por eso ya desde joven fue reconocido como especialista en ellas. Hay una muestra de eso en el hecho de que el humanista Adrian de Jonghe sometiera a la revisión del español su Commentarium de Horacio. Lo cuenta el autor neerlandés en carta a Gonzalo Pérez (puesto que el propio Verzosa, tras revisar el libro, le recomendó dedicarlo a Pérez) fechada en Haarlem el 1 de agosto de 1552:

[...] cui [sc. Verzosae], quum eos superiore anno legendos et Aristarchaea cura examinandos tradidissem $[\ldots]^{44}$

${ }^{41}$ Quizás este error se deba a dos glosas marginales (incluso ajenas al autor) que intentasen explicar el sentido de la construcción correcta $a c$ tu escribiendo a su lado la equivalencia quam tu. El copista pudo entender mejor la glosa explicativa e insertarla, y además escribir erróneamente quam te. Nótese, como hemos indicado antes, que una confusión parecida entre las vocales "u" y "e" puede estar también tras los errores de los versos 42 y 60.

${ }^{42}$ No hemos encontrado documentación sobre una posible producción literaria de Frangipane.

43 Vid. L. Mueller, De re metrica poetarum latinorum praeter Plautum et Terentium libri septem, Hildesheim, 1967, p. 360.

${ }^{44}$ La carta se encuentra en Burgerbibliothek de Berna, ms. B 40 y en Hadr. Iunii epistolae, quibus accedit eiusdem uita et oratio de artium liberalium dignitate nunquam antea edita,

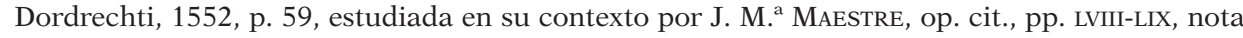
136. Sobre el uso de la biblioteca de Mendoza por parte de Verzosa y la presencia en ella de los libros horacianos véase E. DEL PINO, op. cit., vol. I, pp. LXXXIV-LXXXv. 
Y esa fama de horaciano acompañó a Verzosa también tras su muerte. Se puede ver en la nota biográfica con que Luis de Torres encabezó la edición póstuma de las Epístolas y en los diversos autores que trataron de él en adelante ${ }^{45}$.

\subsection{Comentario al verso 5}

Nos dice Frangipane que hay varios amigos que le impulsan a escribir su composición: Christophoro, Alciati y Filippo Baldo.

El primero de ellos debe de ser, según suponemos nosotros, un Christophoro que aparece en las Epístolas de Verzosa, Christophoro Tanzi, a quien está dedicada la epístola 2, 2646. Por la epístola se ve que este Tanzi tan desconocido debió de ser uno de aquellos novellanti o escritores de avvisi que en muchas ciudades importantes recababan información para sus señores.

La epístola de Verzosa trata de estimular a Tanzi para que ascienda en la Corte vaticana, diciéndole que lo merece tanto como Alciati o Galesio, dos personajes a los que Verzosa también dedicó epístolas, la 2, $8^{47}$ y la 2, $2^{48}$. El primero de ellos es además otro de los amigos que animaba a Frangipane. Se trata de Francesco Alciati, nacido en Milán en 1522, que realizó estudios de Derecho en Pavía y Bolonia y, una vez doctorado in utroque iure, dio clases en la primera de esas ciudades entre 1550 y 1560; y que a finales de este último año fue llamado a Roma por el nuevo papa Pío IV, nombrado referendario de las Signaturas, obispo (5 de septiembre de 1561), datario apostólico (19 de noviembre del mismo año) y finalmente cardenal (12 de marzo de 1565), permaneciendo en la Urbe hasta su muerte ${ }^{49}$. Fue Alciati uno más dentro del abundante grupo de personajes, muchos de ellos lombardos, que trajo Pío IV a Roma como colaboradores para sus proyectos (principalmente la continuación del Concilio); entre esos apoyos hay que contar a sus sobrinos Carlo y Federico Borromeo.

Verzosa dedica su epístola a Alciati probablemente poco después de que este hubiera recibido sus importantes cargos en la Urbe, algo para lo que pudo ser recomendado por Carlo Borromeo, que había sido alumno suyo. En ella Verzosa avisa a Alciati de que algún día aquel trabajo tan intenso

45 Véase L. DE Torres (ed.), Ioannis Verzosae Epistolarum libri IIII, Panhormi, 1577, fols. $3 \mathrm{r}-4 \mathrm{v}$. y, entre los demás, por ejemplo, J. F. ANDRÉs DE UstARROZ, Aganipe de los cisnes aragoneses, Amsterdam, 1781, pp. 27-29: "Imitador de Horacio / en las cultas epistolas, que escribe, / las alabanzas de su ingenio inscribe".

46 Vid. E. DEL PINO, op. cit., vol. II, pp. 636-637.

47 Vid. ibidem, pp. 470-471.

48 Vid. ibidem, pp. 415-417.

49 Vid. F. ARgelati, Bibliotheca scriptorum Mediolanensium, Mediolani, 1745, s.u.; Dictionnaire d'Histoire et de géographie ecclésiastique, Paris, 1912-1967, s.u.; A. LE MIRE, Bibliotheca ecclesiastica, Antuerpiae, 1649, s.u.; S. MiRANDA, The Cardinals of the Holy Roman Church, http:// www2.fiu.edu/ mirandas/bios1565.htm\#Alciati, (consulta de 15 de agosto de 2015); F. PicineLLI, Ateneo dei letterati milanesi, Milano, 1670, s.u.; N. RAPPONI, "Francesco Alciati", en Dizionario biografico degli italiani (Istituto Treccani ed.), http://www.treccani.it/enciclopedia/francescoalciati_\%28Dizionario-Biografico\%29/ (consulta de 15 de agosto de 2015). 
para el Vaticano acabaría haciéndosele pesado y convirtiendo en desagradable el trato con los dos Borromeos.

Y Galesio fue Galesio Regard, otro de los eclesiásticos (este procedente de la Saboya) que Pío IV utilizó en su tarea de reforma eclesiástica. Lo hizo canónigo de San Pedro y presidente de una Comisión beneficiis ecclesiasticis tribuendis desde 1561; y el 15 de octubre de 1563 lo nombró obispo de Bagnoregio a la vez que lo mantenía junto a sís0. En su epístola 2, 2 Verzosa parece recomendarle a un personaje desconocido (que quizás sea él mismo) ${ }^{51}$.

En cuanto a Filippo Baldo (el tercer amigo que estimulaba a Frangipane para escribir), podría tratarse de un noble milanés exiliado, que tuvo que vivir en España, Alemania, Flandes y África, y que fue famoso como narrador de novelas (sobre todo de las de Matteo Bandello) entre las ciudades de Milán y Padua en los años de 1520 y 1530. Como tal aparece en las Novelle de dicho autor ${ }^{52}$. Pero ninguna otra documentación hemos encontrado de su estancia en Roma.

\subsection{Comentario a los versos 12-15}

Estos versos muestran que Frangipane estaba al tanto de cómo era la vida de Verzosa en Roma. Desde al menos 1560 el rey Felipe II había visto la necesidad de erigir en su Embajada de Roma un Archivo histórico. La experiencia había demostrado que multitud de documentos importantes referentes a las relaciones con la Santa Sede, en concreto a privilegios y a sanciones diversas, acababan perdiéndose en el cambio de embajadores, al no haber una persona expresamente encargada de archivar convenientemente esos papeles. Así es que se hicieron las gestiones pertinentes y por fin el 17 de julio de 1562 el Rey firmó la cédula de erección del Archivo y el nombramiento de Verzosa como director del mismo ${ }^{53}$.

50 Cf. N. Rapponi, "Francesco Alciati”, en Dizionario biografico degli italiani (Istituto Treccani ed.), donde también se habla de Galesio Regard: http://www.treccani.it/enciclopedia/ francesco-alciati_(Dizionario-Biografico)/ (consulta de 15 de agosto de 2015); K. EubeL, Hierarchia Catholica Medii Aevi, Monasterii, 1923, vol. III (años 1503-1592), p. 128.

51 Puede verse en E. DEL PINO, op. cit., vol. II, pp. 415-417.

52 Véase La prima parte delle Novelle del Bandello, Lucca, 1554, p. 301; C. Godi, Bandello, Narratori e dedicatari della seconda parte delle Novelle, Roma, 2001, pp. 345-346, 375; R. SAccHI, Il disegno incompiuto. La politica artistica di Francesco II Sforza e di Massimiliano Stampa, Milano, 2005, pp. 62-63; 329-330; 428. Como indica esta última autora en pp. 62-63, la noticia de los viajes de Baldo está dada por el propio Bandello en 1550. Si este Baldo fuese el que aparece en el poema de Frangipane y a su vez este poema fuese (como es nuestra hipótesis que explicaremos en adelante) de 1567, habría que pensar en un Baldo ya casi anciano en la Roma de esa fecha, teniendo en cuenta todos sus viajes anteriores y que en los años treinta ya era conocido como narrador.

53 Se sabe que en una carta de 17 de septiembre de 1560 Vargas respondió al Rey sobre su intención de erigir el Archivo, diciéndole que había comenzado a hacer gestiones para comprar una casa cercana a Sant Giacomo degli Spagnoli y recomendando incluso a Verzosa como director del mismo, aunque quizás Verzosa no conoció esto (o no confió en el éxito de la recomendación) hasta 1562, porque en sus epístolas parece quejarse de su inestabilidad hasta esa fecha. Véase la carta en AGS, Estado, Leg. 886, f. 72 (reproducida en J. LóPEZ DE Toro, op. cit., p. 261) y lo referente a ese periodo vital en E. DEL PINO, op. cit., vol. I, pp. XXXVII-XLI. 
Junto con el nombramiento venían unas "Instrucciones" en español de las que entresacamos estos párrafos:

[...] començeis desde luego a hazer la recollection de las scripturas, assi de las que se fueren despachando de nueuo, como de las expedidas antes, y de todas las que se pudieren hallar, de qualquier calidad que sean, concernientes a nuestros Reynos y estados, conçedidas a mi o a mis antepassados por la Sede Apostolica y summos Pontifices [...] Y quando se fueren expediendo de nuevo algunas Bullas o Breves de conçessiones graçiosas o otras, los originales se nos han de embiar aca [...] pero los transsumptos dellas, autenticos han de quedar en el dicho nuestro Archiuio [...] todas las presentaçiones por nos hechas en su tiempo de los Obispados, Abadias y otras dignidades y beneficios de nuestro patronazgo con las reseruaçiones de pensiones que sobre ellos huuieremos hecho [...] Hareis assimismo recollection de todas las cosas señaladas, como son Indictiones de Conçilios, protestos, Decretos, actos de obediencias notables, de precedençias, differençias de primaçias, sucçesiones, assi nuestras como en el Imperio, y de lo que pudieredes hallar despachado a requisiçion y en fauor nuestro, o de otros prinçipes, que vieredes ser digno de notiçia $[\ldots]^{54}$

Como se ve por estas instrucciones, Verzosa tenía encargado recoger las escrituras concernientes a las relaciones de la Santa Sede con cualquiera de los reinos de Felipe II y de sus predecesores, y enviarlas a los archivos hispanos correspondientes, reservando copia en el de Roma. Esto atañía a las bulas y breves pontificios, así como a las solicitudes hechas desde España o a las presentaciones de obispos o abades y demás dignidades y beneficios en los que entendía la Corona. Finalmente Verzosa debía archivar también toda una multitud de documentos (relacionados con concilios, obediencias, protocolos, precedencias, sucesiones) e informaciones en general que surgieran en Roma y fuesen de interés para Felipe II.

Pero es que además, por vía de hecho, esta tarea informativa se amplió al mundo cultural. Por su cargo Verzosa mantenía frecuente correspondencia con el secretario real Gabriel de Zayas y esta correspondencia manifiesta que el aragonés buscaba también publicaciones interesantes en general, pensadas frecuentemente para el incipiente fondo de la Biblioteca de El Escorial. Así por ejemplo, en una carta de 1 de febrero de 1567 Verzosa dice a Zayas:

\footnotetext{
A los XVIII, del passado scriui largo a v. m. acerca de lo tocante al Arquiuo y librería de Su Md. ${ }^{55}$ lo que al presente se me offresce es, que yo ando buscando libros, y he dado orden a un librero el mas prinçipal desta çiudad que me vaya poniendo aparte los que fueren saliendo, y me haga yndice dellos. La librería del Cardenal Carpi se vende $[\ldots]^{56}$
}

A partir de aquí utilizaremos las siguientes siglas: AGS, Archivo General de Simancas; BAH, Biblioteca de la Real Academia de la Historia en Madrid.

54 Véase AGS, Estado, leg. 892, doc. 68, ff. [2v-3r]; lib. 20, f. [6v-7r]; lib. 75, f. 47r-[47v]; reproducido en J. LÓPEZ DE TORO, op. cit., p. 274, doc. XVII; y estudiado en J. M. ${ }^{a}$ MAESTRE, op. cit., pp. LXXVII-LXXVIII.

55 Entiéndase la Biblioteca de El Escorial.

56 Véase AGS, Estado, Leg. 904, f. 60, reproducido en J. LóPEZ DE TORO, op. cit., p. 262. 
Y, sobre todo, la correspondencia entre Verzosa y Gabriel de Zayas (el mismísimo Secretario de Estado de Felipe II) descubre que a Verzosa le eran requeridas informaciones de todo tipo (como ya avanzaban las "Instrucciones") que pudieran tener interés para la Corte hispana. Veamos una muestra:

\begin{abstract}
Aquí va la oration de la obediençia de Françia que dio Justo de Tornon hela sacado por via de un amigo mio Senes que esta con Ferrara. Su Magd. sera seruido de vella, ellos no la han querido publicar por miedo de los Hugonotes que los tractan mal y a la Reyna madre muy bien por el contrario y tambien por çiertos otros puntillos como vera su Magd. Los titulos de los Reyes de Francia que hay en ella; saco Vitelo de los Registros desta Sede y los dio al Auctor de la oraçion. Tambien va una Relaçion pequeña de lo del Mundo, a sus tiempos embiare siempre otras por que de aquí se ve y trasluze todo lo que en el passa. ${ }^{57}$
\end{abstract}

En definitiva, se puede ver que Verzosa era uno más de aquellos novellanti de los que hablábamos antes, que informaba a Zayas y al Rey. Estos personajes eran en muchos casos auténticos espías, en cuanto que parte de la información a la que accedían era secreta y lo hacían con métodos cualesquiera, lícitos o no ${ }^{58}$. Pero, por otro lado, una parte de la información que manejaban no era confidencial (y la difundían también en pliegos de venta pública) y hacían muchas gestiones no confidenciales para sus señores (por lo que eran llamados agentes) ${ }^{59}$.

De todo esto se deduce que no es extraño que Frangipane elogie a Verzosa en sus versos 12-15 por su atención a quidquid fit Romae (a todo lo que ocurría en Roma, empezando por los cargos que vacaban o la salud de los cardenales) y por su destreza en gestionar ante unos y otros lo que el Rey le encargaba (la solicitud de cargos para los hispanos o la relación con los cardenales de ese origen, por ejemplo).

\title{
5.5. Comentario a los versos $18-20$
}

$\mathrm{Al}$ ir leyendo el poema asombra cada vez más el detalle con que Frangipane conocía las actividades de Verzosa, porque en estos versos se refiere a otro de los encargos que el español tuvo en Roma. En las instrucciones que había recibido con su cargo, había una parte latina en la que se concretaban sus deberes, precisando que como resultado de su trabajo debía mantener tres registros o libros. En uno primero debía hacer catálogo de los privilegios y gracias concedidos por la Santa Sede; en el segundo de las presentaciones y concesiones para los beneficios, pensiones y dignidades; y en el tercero una

57 Véase la carta de Verzosa a Zayas de 15 de Marzo de 1567: AGS, Estado, Leg. 904, fol. 65, reproducida en J. LóPEZ DE Toro, op. cit., Epístolas de Verzosa, p. 263.

58 En J. M. ${ }^{a}$ MAESTRE, op. cit., pp. XCVII-XCIX pueden verse muestras irrefutables del espionaje de Verzosa en Roma.

59 Estos personajes son considerados los precedentes de los reporteros y, de hecho, parece que el libro de las Epístolas de Verzosa es uno de los primeros testimonios con que se cuenta sobre su existencia y actividad en el mundo moderno. Vid. E. DEL PINO, op. cit., vol. I, pp. LXVII-LXIX. 
sucinta relación cronológica de lo anterior y de los principales hechos históricos de los que tuviera noticia en Roma. Así se indicaba:

\begin{abstract}
Tertium uero librum sic constituat et ordinet, ab eodem scilicet designato tempore, ut (iuxta Suae Maiestatis litterarum siue instructionum seriem) compendiosam historiam rerum memorabilium texat, breuiter subinde annotatis iis quae secundum temporum rationem in dictis prioribus libris conscribenda sunt, quatenus in eodem Historiae libro, compendioso quodam modo, cum iis quae obseruatione digna uidebuntur, annotata reperiantur et facili negotio temporum et rerum constet, locis obiter obseruatis unde singula desumuntur. ${ }^{60}$
\end{abstract}

Vemos que Verzosa tenía encargado también, por tanto, escribir una narración histórica que recogiese sucintamente los acontecimientos históricos más importantes de los que tuviese noticia en Roma. El carácter conciso de esta crónica histórica hizo pensar a Verzosa en convertirla en unos Annales a imitación de Tácito, abarcando el reinado de Felipe II desde su paso a Inglaterra de $1554^{61}$. Y Frangipane muestra que conocía este aspecto del trabajo de Verzosa (quizás llegó a leer el material) y lo felicita por su obra.

\title{
5.6. Comentario a los versos $24-36$
}

Frangipane admira también que, cuando Verzosa se retira a descansar o le apetece dedicarse a las Musas, lo hace de manera destacada. Diferentes indicios llevan a pensar que esta tarea poética es la composición de las Epístolas y que incluso Frangipane conocía ya la obra en una fase muy avanzada de composición.

En primer lugar, Frangipane indica el tema de los poemas de Verzosa diciendo que tratan de "la forma de pensar, los caracteres, las costumbres y formas de proceder de la actual Corte romana, así como los hechos de cada cual, jóvenes y viejos, que dejaron las comodidades de su dulce patria para vivir en Roma, donde los aqueja la ambición constante y el deseo insano de dinero". Este es ciertamente el contenido y objetivo de las Epístolas, declarado además por su propio autor en la epístola 4, 13 (de las últimas que compuso), en sus versos 12 a 14 :

\section{(...) secli qui facta feracis}

Omnia, qui mores aulae describere quique

Tramite uult alios recto deducere, uti si

Aut Prodicus foret, aut in quadriuiis situs Hermes ${ }^{62}$.

60 Véase AGS, Estado, Leg. 892, doc. 68, f. [3v]; lib. 20 ff. [8r]-[8v]; reproducido en J. LóPEZ DE Toro, op. cit., p. 275 y en J. M. a MAESTRE, op. cit., p. LXXXI-LXXXII.

${ }^{61}$ En esa fecha comenzó Verzosa a vivir en su Corte y Felipe II comenzó a terner título de rey, el de rey de Nápoles, que Carlos V le cedió para que acudiese con él a la boda con María Tudor. Sobre la conversión del encargo en libro de historia, véase J. M. ${ }^{a}$ MAESTRE, op. cit., pp. LXXXI-XCI.

62 Vid. Verz. epist. 4, 13, 12-14 (E. DEL PINO, op. cit., vol. III, pp. 1274-1275): “(...) quien quiere [el propio autor] describir los acontecimientos de este siglo feraz y las costumbres de la 
Y en segundo lugar añade Frangipane que Verzosa hace "todo ello en unos poemas tan agradables, y con un arte a la vez tan exquisito y sencillo, que el poeta Horacio lo haría igual si volviese a la vida", lo que remite sin duda a las horacianas Epístolas.

\subsection{Comentario a los versos $37-41$}

En estos versos Frangipane habla sobre el ingenio y carácter jocoso de Verzosa. Es posible que el italiano se refiera al carácter real de su amigo, que conocería por el trato. Pero es llamativo que el propio Verzosa se describa a sí mismo de la misma manera en un pasaje de las Epístolas:

Historiis me, Galle, tuis tandem assue, ut omnes
Concelebrent coetus et spissa Trapezia, et Vrbis
Sit nullus coetus nec deuius angulus in quem
Non penetret Verzosa tuus rumore iocoso. ${ }^{63}$

\subsection{Comentario a los versos $42-46$}

Tal es la bondad del carácter de Verzosa, dice Frangipane, que es famosa incluso para el Papa y los monseñores, y también para los embajadores (en especial el que en ese momento vuelve a España y que bien conoce los méritos de Verzosa para con el Rey). ¿Quién puede ser ese embajador que vuelve a la Corte de Felipe II? En realidad, por lo que se sabe, Verzosa pasó varias veces por la experiencia de ver partir para España al embajador y quedarse él en la Embajada de Roma: en 1553, en que fue retirado Hurtado de Mendoza; en 1563, cuando el 12 de octubre de ese año se marchó Francisco de Vargas; y en 1567 cuando en la primera parte del año (el 2 de junio estaba ya en España) lo hizo Luis de Requesens. Debemos descartar que Frangipane se refiera al primer relevo por demasiado temprano y entre los otros dos nos inclinamos a pensar en el último por los siguientes motivos.

Es cierto que hay constancia de la amistad que Verzosa tuvo con Francisco de Vargas. Se habían conocido en fecha tan temprana como 1547 en el Concilio, al que asistió Vargas como experto jurista, y Verzosa le dedicó la epístola 1, 11, datable en 1554, deseando visitarlo en Venecia cuando Vargas era embajador allí. Luego además estuvieron juntos en la Embajada de Roma entre 1559 y 1563, y fue el mismo Vargas quien recomendó a Verzosa para dirigir el Archivo.

Pero sin embargo, el texto de Frangipane debe de ser posterior a 1563, puesto que cita con detalle (y no como incipientes) todas las actividades que

Corte, para guiar a otros por un camino recto, como si fuese un Pródico o un Hermes puesto en las encrucijadas". Además, ya en una carta a Jerónimo Zurita escrita en Hampton Court el 29 de mayo de 1555 dice de las Epístolas que "son morales, y de cosas presentes, y tratos de la vida".

63 Vid. Verz. epist. 2, 19, 1-4 (E. DEL PINO, op. cit., vol. II, pp. 558-559): "Inclúyeme, Gallo, por fin, en tus historias, para que me celebren todas las reuniones y los frecuentados Trapecios. Y para que no haya reunión en Roma, ni rincón apartado al que no llegue tu Verzosa con un rumor jocoso". 
se encargaron a Verzosa el año anterior; e incluso cabría decir que debe de ser bastante posterior a 1563, porque da por hecho que ya la crónica histórica está avanzada y es muy conocida por todos.

Con Luis de Requesens coincidió Verzosa en Roma entre 1564 y 1567. No consta que se conocieran antes, por cuanto que Requesens había permanecido hasta entonces principalmente en España y no parece haber podido coincidir con el aragonés. Además, la estancia de Requesens en Roma se redujo en realidad al periodo de 1565-1567, porque fue retirado temporalmente el 14 de julio de 1564, justo poco después de llegar, como protesta por las diferencias en el trato protocolario, y no volvió hasta agosto de 1565.

Pero Verzosa trató de medrar con él. De hecho, cuando el embajador regresó a Roma le dedicó una epístola que terminaba así:

De me, (si quicquam tibi me promittere fas est),
Quantulacunque animi uis est et corporis huius
Fortunaeque meae, trepidae experientia uitae
Quaecunque est, quocunque trahent aut tempora ducent,
Vsibus impendam illa tuis ubicunque locorum.
Aut nutu et clamore sequar, si pondera rerum
Non poterunt humeri fulcire immensa tuarum. ${ }^{64}$

En este pasaje conciliatorio Verzosa ofrece sus servicios rendida y elegantemente al embajador, pero implícitamente está solicitando nuevo y mejor status. De forma que es muy posible que la epístola de Frangipane fuese compuesta en la primera mitad del año 1567 cuando Requesens marchaba para España.

Además, se sabe que ya Verzosa había utilizado la misma táctica: pedir a un embajador que viajaba a Madrid que le recomendase en la Corte. Se trató de Juan de Ayala, un embajador extraordinario que Felipe II mandó a Roma en 1561 para asegurar que el Papa no convocaba nuevo concilio sino reanudación del que quedó en suspenso en 1552. Al menos Verzosa, en una epístola en verso que escribió para Ayala, a quien conocía desde antiguo, le indicaba:

Dic tamen ut scriptis certos discernat amicos Muneribusque suis, sanctam in Sedemque refundat Quicquam ex iis, quae sponte et donauit abunde. ${ }^{65}$

64 Vid. Verz. epist. 3, 1, 16-22 (E. DEL PINO, op. cit., vol. III, pp. 800-801): "En cuanto a mí, (si se me permite hacerte algún ofrecimiento), toda la fuerza de este espíritu y de este cuerpo, por poca que sea, y la de mi fortuna; toda la experiencia, sea mucha o poca, de mi agitada vida; donde sea que las circunstancias me arrastren o me lleven; todo lo emplearé en tu servicio, en cualquier lugar que me encuentre. $\mathrm{O}$, si no pueden mis hombros sostener el peso enorme de tus asuntos, contarás con el apoyo de mi gesto y de mi voz".

65 Vid. Verz. epist. 1, 31, 22-24 (E. DEL PINO, op. cit., vol. I, pp. 298-299): "Dile, no obstante, que por los escritos distinga a sus amigos fieles, y por sus cargos. Y que envíe alguno de ellos hacia la Santa Sede, ya que antes los regaló de grado y con abundancia". 


\subsection{Comentario a los versos $48-62$}

Aquí Frangipane recomienda a Verzosa que se conforme con su suerte. $\mathrm{Y}$ es que por su correspondencia sabemos que el aragonés nunca se sintió satisfecho con su cargo de director del Archivo y aspiró a más. Hizo varios intentos en este sentido ante la Corte de Madrid precisamente no mucho después del regreso a ella de Luis de Requesens. En una carta a Zayas del 1 de julio de 1569 decía:

Mire V.m. que es verguença y el mundo se marauilla que despues de xvi años de seruicio continuo sin los que serui al Emperador y con tantas galanterias y estar para seruir con fuerças y animo no tenga una pension o pieça en esta Ytalia a lo menos. ${ }^{66}$

\section{Y el 7 de agosto siguiente insistía:}

La Señora Doña Ana Gonçales esta algo mala. Tiene dos Carlanias en mi tierra que valen ccc libras, cosa que (lo que no querria yo) muriese la dicha Señora, me estaria bien por ser cosa de mi patria y romper (despues de xx años de seruicio importante y continuo) el ojo al diablo. Espero que Su Mgd. me hara esta merced sea por auiso que yo auisare de lo que sucediere y v. m. en este medio hara lo que mas le paresciere cumplir para el effecto desto o, de otra merced eclesiastica, o seglar, pues uee que no ay rayz en que estriuar. ${ }^{67}$

Aparte del propio carácter ambicioso que pudiera tener Verzosa, hay que considerar también que el sistema de ingreso y ascenso en las cortes de aquella época (también la pontificia) no se regía por ningún sistema objetivo y el bueno de Verzosa veía cómo pasaba el tiempo y otros, con menos estudios o años de servicio (en particular en Roma ayudados por su origen italiano o por tener las órdenes sagradas), ascendían con más rapidez y ocupaban puestos que él apetecía. De hecho, él mismo, que permaneció soltero toda su vida, se planteó recibir las órdenes por este motivo y se lo dijo a Zayas en carta del 2 de noviembre del mismo año:

Acerca de mi particular, estoy en tomar habito largo, no por ambicion ni deseo de mas, sino por tener mas comodidad para seruir a su Magd. a quien sera mas oportuno darmela de aquella manera que desta con mill occasiones que aca y alla se offrecen cada dia de cosas que las lleua gente incongnita e inútil. ${ }^{68}$

Admira cómo Frangipane estaba al tanto de toda esta situación interior de Verzosa. Reconoce que el español podría haber merecido un episcopado o el cardenalato incluso. Pero ve preferible que siga dedicado a la escritura y publicación de sus Epístolas, las que serán la clave de la gloria futura del autor y de sus destinatarios (entre los que quiere contarse el mismo Frangipane). Así, además, no tendrá preocupaciones que le quiten el sueño. Dice Frangipane:

66 Véase AGS, Estado, Leg. 911, fol. 150; reproducido en J. LóPEZ DE Toro, op. cit., p. 270.

67 Véase AGS, Estado, Leg. 911, fol. 151; reproducido ibidem.

68 Véase ibidem, p. 278. Este tema está tratado en E. DEL PINO, op. cit., vol. I, pp. XLI-XLII. 
Interea Frangipanis [...]

te salvere iterum iubet ac deponere curas

ingentes animo, dulces quae carpere somnos

nec gustare sinunt gratae solatia uitae

El italiano podría conocer el insomnio del español por su relación de amistad, pero no deja de extrañar la coincidencia de que el propio autor de las Epístolas hable en ellas de la misma cuestión:

Dum expergiscere, dum surgis, dum pandicularis,

It seclum. Interea grauibus uigil aestuo turbis,

Quas procul amosset lux prima, liber uel amicus. ${ }^{69}$

Y por tanto cabe suponer con bastante fundamento que Frangipane conocía bien todas las Epístolas del español. Coincide que la obra estuvo a punto de ser publicada en aquel año de 1567. Al menos Verzosa lo esperaba así, según cuenta al propio Felipe II en una carta de 15 de marzo de 1567, donde también le informa del gran avance de la historia que escribía sobre su reinado (y cuyo manuscrito quizás también conoció Frangipane):

La Historia se esta puliendo. Espero que contentara a su Magestad, y asi por ella como por las Epistolas (que se estamparan presto) se hara este siglo celebre memorable. ${ }^{70}$

Así que el friuliano estaba al tanto de todo esto y se suma de pasada, quizás en lo que se consideraba el último momento, al número de aquellos que solicitaron a Verzosa aparecer en el libro ${ }^{71}$.

Nada de esto debe extrañarnos, puesto que hubo varios momentos en la vida del español en que éste sintió cercana la publicación de las Epístolas (obra que estuvo ampliando y retocando casi toda su vida ${ }^{72}$ ). Justamente por esto es lógico suponer que desde temprano tuvo preparado un amplio epistolario en verso y se sabe que durante largos años el autor lo fue dando a conocer sin rubor. En su epistolario en prosa hay rastros de cómo envió epístolas a los propios destinatarios de las mismas, o las envió a otros para darlas a conocer. Consta, por ejemplo, el envío a Jerónimo Zurita y al cardenal Granvela de las epístolas a ellos dedicadas; y muy posiblemente envió también la suya a Onofrio Panvinio ${ }^{73}$. También consta que envió a Zurita las epístolas

${ }^{69}$ Es el comienzo de una epístola para su criado. Vid. Verz. epist. 1, 43, 1-3 (E. DEL PINO, op. cit., vol. I, pp. 382-383): "Mientras te despiertas, mientras te levantas, mientras te estiras bostezando, pasa un siglo. Mientras tanto, yo doy vueltas, despierto, a mis graves preocupaciones, que ojalá el amanecer, un libro o un amigo hubiesen disipado".

${ }^{70}$ Véase AGS, Estado, Leg. 904, fol. 65; reproducido en J. LÓPEZ DE TORO, op. cit., pp. XXXVI y 263

${ }^{71}$ Consta que así lo hizo también al menos el zelandés Ioachim Polites, según se ve en E. DEL PINO, op. cit., vol. II, pp. 571-603.

72 Estos momentos fueron en 1555, en 1565 (por Pío IV), en 1567, 1569 y 1572. Así lo manifestó en diversas cartas que pueden verse citadas en E. DEL PINO, op. cit., vol. I, pp. LI-LIII.

73 Véase E. DEL PINO, op. cit., vol. I, pp. 74-99; vol. II, pp. 562-567; vol. III, pp. 896-907. 
para Juan Manrique de Lara y para Antonio Agustin: en la carta de Verzosa a Zurita de 19 de septiembre de 1555, decía: "Con el primero irà una espistola a Don Ioan Manrique del oficio de Embaxador Romano y otra del Auditor Antonio Agustin de la Rota, que hize este verano"74. Y se sabe además que Honorato Juan tuvo un cierto número de epístolas que dio a conocer a otros: Zurita en carta desde Madrid muy probablemente del mismo 1555 decía a Verzosa: "excelentes, quales me han parecido todas las [epístolas] que yo he visto que me mostrò el señor Honorato Ioan"75.

Como se sabe, en aquella época era habitual dar a conocer composiciones poéticas como estas antes de su paso por la imprenta. Quizás en el caso de Verzosa esto formaba parte también de una política calculada para dar a conocer la obra o para ganar el favor de un prócer u otro. De cualquier manera, incrementaría la difusión de estas piezas el que su autor considerase que iban a ser de pronta publicación. Y de esta forma, siguiendo un plan ideado o no, el libro se fue constituyendo en un conocido retrato de época, no siendo difícil que surgieran algunos personajes a los que apeteciera aparecer en él.

Como decimos, este es también el caso de Giacinto Frangipane. Su epístola a Verzosa, llena de consejos "horacianos" donde los haya, es una muestra de reconocimiento hacia el autor español y hacia sus Epístolas, a la vez que una solicitud de pasada para ser incluido en estas últimas. Por lo que sea, Verzosa no llegó a componer esa epístola para Frangipane o no se nos ha conservado. En la dispersión de libros y papeles que supuso la muerte del español, las epístolas quedaron irónicamente (si pensamos en todos los intentos previos de publicación) como una obra manuscrita, inacabada y abierta, finalmente publicada por el sobrino de un amigo. Pero en cualquier caso el poema de Frangipane que conserva la Biblioteca Vaticana, correctamente contextualizado, nos deja otra muestra más de la viva influencia de Horacio en los círculos intelectuales de la Roma de la segunda mitad del siglo XVI.

ABSTRACT: The Vatican Library holds an unedited manuscript (ms. Vat. lat. 5225, iv, f. $879 r-880 r$ ) attributed to the Italian bishop Giacinto Frangipane. This paper includes the first critical edition, translation and study of the aforementioned text. In our study, we contend that the text is a Horatian epistle composed as a receptio of the Spanish humanist Juan de Verzosa's Epistolarum libri. We also argue a hypothesis about the epistle place and date of composition: Rome in 1567, which exemplifies Horace's strong influence over the writers of Renaissance Rome, even in such a late stage as the second half of the $16^{\text {th }}$ century.

KEY wORDs: Classical Tradition of Horace; Latin Humanism; Renaissance Rome.

74 Véase en BAH, Salazar, 9/112, 535r-536v; D. J. DoRmer, Progresos de la historia en Aragón, Zaragoza, 1680, pp. 491-493.

75 Véase BAH, Salazar, 9/112, 532r.534r; D. J. DoRmer, op. cit., pp. 552-553. 



\section{I \\ COMMENTATIONES}

Antígona: luzes e sombras - ANA PaUla Pinto

Qui sont les rotae dans les Res Rusticae (II, 1, 5) de Varron? - Marcel Meulder ........ 31

Athènes historique, Athènes éternelle. Le regard de Plutarque sur la ville et ses monuments - FrançOISE FraZIER

La mirada de Plutarco: significados y funciones de su testimonio visual en las Vidas Paralelas - CARLOS ALCALDE-MARTín

Tra Costantinopoli e Vivarium: fonti greche e fonti latine nel Commento ai Salmi di Cassiodoro - PATRIZIA StOPPACCI.

Los progymnasmata de Aftonio publicados por Palmireno en 1552: estudio de un ejemplar localizado en la Biblioteca Nacional de Portugal - M.A Violeta Pérez CUstodio

En la estela de Horacio: una epístola latina inédita de Giacinto Frangipane

- EduARdo del Pino González

Los progymnasmata en los Praeceptionum rhetoricarum libri $V$ et exercitationum libri II de Georg Henisch: fuentes y materiales - GREGORIO RODRíGUEz HERRERA

Entre a fidelidade às origens e o contexto interpretativo: duas adaptações portuguesas contemporâneas da tragicidade ambígua de Antígona - MARIA José FERREIRA LOPES .

\section{II \\ STVDIA BREVIORA}

El análisis de los datos sobre la religión prehelénica: una cuestión metodológica Marcello Tozza.....

Sobre la prudencia de un Cicerón demasiado hábil: De inventione 1, 49, 91 a propósito de Cornelia, madre de los Gracos - MARc MaYer y Olivé.

Virgil's Smooth-Talking Pygmalion and Jerome's Commentaries on Mordiloquent Minor Prophets - NeIL AdKIN......

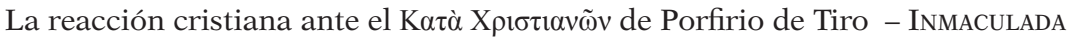
Rodríguez MORENO.

El viaje de Trezenzonio a la isla de Solistición. Refacción de material y distintos niveles de sentido - Joel VARELA RodRíGUEZ 
La Austriaca siue naumachia de Francisco de Pedrosa y la propaganda al servicio del poder - JuAN CARLos Jiménez del CASTILlo .....

La apología de la Biblia Regia escrita por Benito Arias Montano: un documento en paradero desconocido - ANTONIo Dávila Pérez

El descenso al infierno del Ovidio de Vintila Horia en la novela Dios ha nacido en el Exilio. Diario de Ovidio en Tomis - AlEJANDro Martínez Sobrino.

\section{VARIA NOSCENDA}

Iscrizioni romane di tradizione manoscritta: il codice epigrafico di Aquiles Estaço - Alejandra Guzmán Almagro ....

\section{IV}

\section{LIBRI RECENSITI}

\section{a) Edições de texto. Comentários. Traduções. Estudos Linguísticos}

Esouilo, Tragedias IV: Coéforos. Euménides, introducciones y texto por Francisco Rodríguez Adrados, traducciones y notas por Esteban Calderón Dorda - RUI Miguel DuARTe

Sófocles, Icneutas, os sátiros rastreadores: fragmentos de um drama satírico reconstituído para a contemporaneidade com base nos aparatos de Stefan Radt e Hugh Lloyd-Jones. Tereza Virgínia Ribeiro Barbosa (org.) - Sofia Frade ....

María Teresa Gallego Pérez, Vida y muerte en el Corpus Hippocraticum - Maria José Mendes e Sousa

PolyBius, The Histories, vol. VI: books 28-39, translated by W. R. Paton, revised by Frank W. Walbank and Christian Habicht; Unattributed fragments, edited and translated by S. Douglas Olson - Rui Miguel DuARTE

Marco Terêncio Varrão, Das coisas do campo. Tradução, introdução e notas de Matheus Trevizam - Manuel José De Sousa BARBosa

VIRGílio, Geórgicas I. Org. Matheus Trevizam, traduções de António Feliciano de Castilho e Matheus Trevizam - ANA FILIPA Gomes FerReIRA

Tibulo, Poemas (Cantos de Amores). Tradução, introdução e notas de Carlos Ascenso André - Luís CERqueira.

Francesco Citti, Cura sui. Studi sul lessico filosofico di Seneca - Ana Filipa Silva.......

Sandrine Dubel (ed.), Jackie Pigeaud (postfac.), Lucien de Samosate. Portrait $d u$ Sophiste en Amateur d'Art - Nuno SimõEs Rodrigues 
Juan Antonio López Férez (ed.), Galeno. Lengua, composición literaria, léxico, estilo - InMACUlada Rodríguez Moreno .....

S. Douglas Olson (ed.), Athenaeus: The Learned Banqueters. Volume VII: Books 13, 594b-14 - Fotini HaDJITTOFI

CALCIDio, Traducción y Comentario del Timeo de Platón. Introducción, traducción y notas de Cristóbal Macías Villalobos - INÊs BoLINHAS

Nonnus of Panopolis, Paraphrasis of the Gospel of John XI. Edited by Konstantinos Spanoudakis - Fotini HadjITTOFI.

Enara San Juan Manso, El Commentum Monacense a Terencio - Eftychia BATHRELLOU .

Navigatio sancti Brendani, Alla scoperta dei segreti meraviglosi del mondo, edizione critica a cura di Giovanni Orlandi e Rossana E. Guglielmetti, introduzione di Rossana E. Guglielmetti, traduzione italiana e commento di Giovanni Orlandi - ARNALDo Do EsPíRITO SANTO.

D. Jerónimo Osório, Opera Omnia. Tomo II: Epistolografia. Estabelecimento do texto latino por Sebastião Pinho e António Guimarães Pinto. Introdução, tradução, notas e comentários de António Guimarães Pinto - MARIa Luísa RESENDE.

D. Jerónimo Osório, Opera Omnia. Tomo III: Comentários aos Provérbios de Salomão. Estabelecimento do texto latino por Sebastião Pinho e António Guimarães Pinto. Introdução, tradução, notas e comentários de António Guimarães Pinto - Maria Luísa Resende....

\section{b) Literatura. Cultura. História}

António José Gonçalves de Freitas, Os Deuses e a Origem do Mundo - Maria João CORREIA SANTOS.....

Franco Montanari, Stephanos Matthaios, Antonios Rengakos, Brill's Companion to Ancient Greek Scholarship, vol. 1: History. Disciplinary profiles; vol. 2: Between theory and practice - Nereida Villagra .....

Richard Bouchon, P. Brillet-Dubois, Nadine Le Meur-Weissman (eds.), Hymnes de la Grèce Antique. Approches littéraires et historiques. Actes du Colloque international de Lyon, 19-21 juin 2008 - ABEL N. PENA

André Laks, Rossella Saetta Cottone (dir.), Comédie et philosophie. Socrates et les 'Présocratiques' dans les Nuées d'Aristophane - Rui Miguel DuARTE

Victoria Wohl, Euripides and the Politics of Form - SofIA Frade

Juan Antonio López Férez, Mitos en las obras conservadas de Eurípides. Guía para la lectura del trágico - José Vela TeJADA 
Robert Mayhew, The Aristotelian Problemata Physica. Philosophical and Scientific Investigations - BERNARDO MACHADO MOTA

André Hurst, Dans les marges de Ménandre - EfTychia Bathrellou

Joaquim S. Pinheiro, Tempo e espaço da paideia nas Vidas de Plutarco - Ramiro GonZÁlez Delgado

Joseph GeIger, Hellenism in the East. Studies on Greek Intellectuals in Palestine FOTINI HADJITTOFI

Gesine Manuwald, Astrid Voigt (eds.), Flavian Epic Interactions - Ana Maria Lóio...

Yvan Nadeau, Dog Bites Caesar! A Reading of Juvenal's Satire 5 (with Horace's Satires I, 5; II, 5; II, 6; Epistles I, 1; I, 16; I, 17) - Maria CRIstina Pimentel

Andrea LaI, Alle nozze dello Sposo. Gregorio Magno commentatore del 'Cantico dei cantici' e le sue fonti - AMÉRICO PEREIRA

Cécile Bost-Pouderon, Bernard Pouderon (eds), Les Hommes et les Dieux dans l'ancien roman. Actes du colloque de Tours, 22-24 octobre 2009 - GIUSEPPE CiafARDONE

Cristina-Georgeta AleXandrescu (ed.), Cult and votive monuments in the Roman Provinces, Proceedings of the $13^{\text {th }}$ International Colloquium on Roman Provincial Art (Bucharest, Alba Iulia, Constanta, 27 $7^{\text {th }}$ May $-3^{\text {rd }}$ June 2013 - within the framework of Corpus Signorum Imperii Romani) - MARIA João CorreIA SANTOS

Rosario Moreno Soldevila, Juan Martos (eds.), Amor y sexo en la literatura latina - Maria JoÃo Correia Santos

Juan Antonio López Férez (ed.), La comedia griega en sus textos. Forma (lengua, léxico, estilo, métrica, crítica textual, pragmática) y contenido (crítica política y literaria, utopía, sátira, intertextualidad, evolución del género cómico) - José VELA TEJADA

JoËL Thomas, Mythanalyse de la Rome Antique. Pref. Paul Veyne - Nuno Simões RODRIGUES

Aline Estèves, Jean Meyers (eds.), Tradition et innovation dans l'épopée latine, de l'Antiquité au Moyen Âge - Luís M. G. CERoueIra....

Arnaud Perrot (ed.), Les Chrétiens et l'Hellénisme. Identités religieuses et culture grecque dans l'Antiquité tardive - RuI Miguel DuARTE

STÉPHANE RATTI, Antiquus error: Les ultimes feux de la résistance païenne 'Scripta uaria' augmentés de cinq études inédites - MARIA JoÃo CoRrEIA SANTOS.

António Manuel lopes Andrade, Carlos de Miguel Mora, João Manuel Nunes TORRÃo (coords.), Humanismo e ciência. Antiguidade e Renascimento - LuANA GIURGEVICH 
Belmiro Fernandes Pereira, Retórica e Eloquência em Portugal na Época do Renascimento - MARIA Luísa ReSENDE..

Alejandro Coroleu, Printing and Reading Italian Latin Humanism in Renaissance Europe (ca. 1470 - ca.1540) - MARIA Luísa RESENDE

A. Castro Santamaría, J. Garcia Nistal (coords.), La impronta humanística (ss. XV-XVIII), saberes, visiones e interpretaciones - MADALENA BRITO.

Jerry Toner, Homer's Turk: How Classics Shaped Ideas of the East - RuI Carlos FONSECA

Sergio Audano, Classici lettori di classici. Da Virgilio a Marguerite YourcenarGiUSEPPE CiAfARDONE

Timothy Saunders, Charles Martindale, Ralph Pite, Mathilde Skoie (ed.), Romans and Romantics - RICARDO NOBRE

Francisco Rodríguez Adrados, El cuento erótico griego, latino e índio. Ilustrações de Antonio Mingote - Hiteshrumar Parmar

Francisco Rodríguez Adrados, El Río de la Literatura. De Sumeria y Homero a Shakespeare y Cervantes - JoAQuim PINHEIRO.

Belmiro Fernandes Pereira, Jorge Deserto (ed.), Symbolon III: Paz e Concórdia; Belmiro Fernandes Pereira, Ana Ferreira (ed.), Symbolon IV: Medo e Esperança - RicARDO NOBRE.

Cristina Santos Pinheiro, Anne Martina Emonts, Maria da Glória Franco, Maria JoÃo Beja (coords.), Mulheres: Feminino, Plural - Vanda Anastácio.....

Il senso del Medioevo: In memoriam di Claudio Leonardi, a cura di Antonella Degl'Innocenti, Donatella Frioli, Paolo Gatti, Fabrizio Rasera - ManUEL José DE Sousa Barbosa

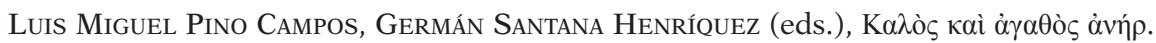

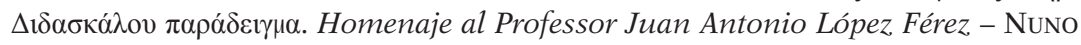
SIMÕES RODRIGUES.

IÑIgo Ruiz ARZalluz (coord.), Estudios de Filología e Historia en Honor del Profesor Vitalino Valcárcel, 2 vols., edição de Alejandro Martínez Sobrino, Maria Teresa Muñoz García de Iturrospe, Iñaki Ortigosa Egiraun e Enara San Juan Manso Maria Fernandes.

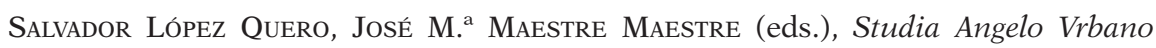
Dicata - ANDRÉ SimõES .....

Cristóbal Macías Villalobos, José M. ${ }^{a}$ Maestre Maestre, Juan F. Martos Montiel (eds.), Europa Renascens. La Cultura Clásica en Andalucía y su proyección europea - ANDRÉ SIMÕES. 
Este XLIV volume da Nova Série de Euphrosyne foi composto, impressso e encadernado em Braga, nas Oficinas da PUBLITO - Estúdio de Artes Gráficas, Lda.

Dezembro de 2016 


\title{
E V P H R O S Y N E
}

\author{
REVISTA DE FILOLOGIA CLÁSSICA \\ Centro de Estudos Clássicos - Faculdade de Letras \\ PT - 1600-214 LISBOA \\ centro.classicos@letras.ulisboa.pt
}

\section{ARTICLE SUBMISSION GUIDELINES}

1. Euphrosyne - Revista de Filologia Clássica, the peer journal of the Centre for Classical Studies, publishes papers on classical philology and its disciplines (including classical reception and tradition).

2. Papers can be sent to centro.classicos@letras.ulisboa.pt or to the Centre for Classical Studies' post mail.

3. Papers submitted: must be original; cannot be yield to other entity; must be sent in their definite version; have to be presented according to these guidelines; will not be returned to the author. Papers will be submitted to peer reviews.

4. Papers will be accepted until $31^{\text {st }}$ of December in the year previous to publication; an acceptance notification will be sent to the author until $30^{\text {th }}$ of April in the year of publication.

5. Originals must always be submitted in double electronic format (Word/.doc(x) and PDF).

6. Papers must have: a) title (short and clear); b) author's name and surname; c) author's academic or scientific institution; d) author's email; e) abstract (10 lines) in English; f) three key-words in English.

7. Recommended size is 10 pages and never more than $20 \mathrm{~A} 4$ pages (font size 12 , double spaced).

8. Notes: endnotes, with sequential numeration. When published, these will be converted to footnotes.

9. References:

a) Remissions to pages within the paper are not allowed.

b) Note references:

Books: J. DE RomilLy, La crainte et l'angoisse dans le théâtre d'Eschyle, Paris, Les Belles Letres, 1959, pp. 120-130; $2^{\text {nd }}$ reference: J. DE RomiLlY, op. cit., p. 78.

Journals: R. S. CALDwelL, "The Misogyny of Eteocles", Arethusa, 6, 1973, 193-231 (vol., year, pp.). $2^{\text {nd }}$ reference: R. S. CALDWELL, loc. cit.

Multi-author volumes: G. Cavallo, "La circolazione dei testi greci nell'Europa dell'Alto Medioevo" in J. Hamesse (ed.), Rencontres de cultures dans la Philosophie Médiévale - Traductions et traducteurs de l'Antiquité tardive au XIVe siècle, Paris, Les Belles Letres, 1971, pp. 47-64.

c) Abbreviations: to Latin authors will be followed ThLL conventions; Liddel-Scott-Jones will be used to Greek authors; Année Philologique to abbreviate journal titles; common abbreviations: p./pp.; ed./edd.; cf.; s.u.; supra; op. cit.; loc. cit.; uid.; a.C./d.C. (roman).

d) Quotations: Must be marked by quotes “..." (but not in Greek); italic is used to highlight words or short sentences; quotations in Latin or Greek must be brief.

10. Images must have quality (preferably in TIF format, minimum resolution 200 p.p.), provided in electronic format, with the precise indication of where they must be placed in the text, and who is their author. The author is responsible for obtaining any copyrights needed.

11. The author will not be provided with more than one set for review, which has to be returned within a week period. Originals cannot be modified.

12. Authors will receive a physical copy of the volume and the electronic version of their paper. 